\title{
LUBUK IKAN LARANGAN SEBAGAI BENTUK KEARIFAN LOKAL DI KAMPUNG KOTO KANDIS KECAMATAN LENGAYANG KABUPATEN PESISIR SELATAN
}

\author{
Fajar Surya Lestari ${ }^{1}$, Paus Iskarni ${ }^{2}$, Yudi Antomi ${ }^{2}$ \\ Program Studi Geografi, \\ Fakultas Ilmu Sosial, Universitas Negeri Padang \\ e-mail:fajar_suryalestari@yahoo.com
}

\begin{abstract}
Abstrak
Penelitian ini bertujuan untuk (1) mengetahui faktor yang mempengaruhi Kampung Koto Kandis dijadikan sebagai lubuk ikan larangan dan (2) mengetahui sistem pelaksanaan kearifan lokal pada lubuk ikan larangan di Kampung Koto Kandis.Metode yang digunakan dalam penelitian ini yaitu metode gabungan (Mixed Method). Sampel penelitian 15 orang dan informan penelitian sebanyak 10 orang. Hasil penelitian yaitu (1) pertama faktor masyarakat Koto Kandis yang berawal dari pemikiran, musyawarah, perencanaan, pengawasan, dan kerjasama masyarakat maka terbentuklah lubuk ikan larangan. Kedua, faktor kondisi fisik Sungai Kapalo Banda sebagai berikut: merupakan alur induk sungai dan merupakan sungai orde I karena tidak ditemui cabang sungai lainnya, sungai ini mengalir mengikuti kemiringan lapisan batuan, dan topografi daerah sekitar sungai didominasi oleh lereng yang datar. (2) Sistem pelaksanaan kearifan lokal lubuk ikan larangan dibentuk pada tahun 2007 oleh masyarakat, masyarakat hanya percaya, lalu memberikan ketenangan, dan makanan untuk ikan-ikan sehingga ikan-ikan tersebut terbiasa hidup dan tidak merasa terganggu. Pada awalnya dikatakanlah menggunakan unsur mistis, hal ini bertujuan agar tidak ada masyarakat yang mengambil ikan, namun faktanya lubuk ini tidak menggunakan unsur mistis apapun.
\end{abstract}

Kata Kunci: Kearifan Lokal, Ikan Larangan

\begin{abstract}
This study aims to (1) find out the factors affecting Kampung Koto Kandis serve as the prohibition of fish holes and (2) to know the system of local wisdom implementation in the prohibition of fish in Kampung Koto Kandis.The method used in this research is the Mixed Method. Research Samples are taken as many as 15 people and 10 respondents. The result of this research is to find out (1) the factors that influence the area is used as the prohibition of the focus to two factors, namely: the first factor of Koto Kandis society that originated from the thinking, musyawarah, planning, supervision and community cooperation hence formed the fish. Second, the physical condition: Kapalo Banda River is the main river flow and is the first order river because it is not encountered by other river branches, the river flows following the slope of the rock layer, and the topography of the area around the river is dominated by a flat slope.2) The system of local wisdom of fish prohibition in Kampung Koto Kandis accepted and formed in 2007 by people Koto Kandis, people just believe, then provide peace, and food for the fish so that the fish are used to life and do not feel disturbed. it is intended that no people take fish, but in fact this does not use any mystical element.

Keywords: Local Wisdom, Fish Prohibition
\end{abstract}

\footnotetext{
${ }^{1}$ Mahasiswa Program Studi Geografi untuk Wisuda September 2017

${ }^{2}$ Dosen Jurusan Geografi Fakultas Ilmu Sosial Universitas Negeri Padang
} 


\section{PENDAHULUAN}

Sungai merupakan sumberdaya milik bersama sehingga pemanfaatan dan penggunaanya dapat dilakukan oleh masyarakat secara umum.Proses perkembangan dan pemanfaatan sumberdaya sungai telah memunculkan banyak pengetahuan dan tata nilai tradisional yang dihasilkan dari proses adaptasi dengan lingkungannya salah satu bentuk pengetahuan berupa kearifan lokal.

Kearifan lokal dianggap pandangan hidup dan ilmu pengetahuan serta berbagai strategi kehidupan yang berwujud aktivitas yang dilakukan oleh masyarakat lokal dalam menjawab berbagai masalah dalam pemenuhan kebutuhan mereka (dalam situs Departemen Sosial RI). Kearifan lokal bukan sekedar nilai tradisi atau ciri lokalitas semata melainkan nilai tradisi yang mempunyai daya-guna untuk mewujudkan harapan atau nilai-nilai kemapanan yang juga secara universal yang didamba-damba oleh manusia dan salah satu kearifan lokal yang berkembang adalah pelestarian lubuk ikan larangan.

Pelestarian lubuk ikan larangan inilah yang diciptakan oleh masyarakat yang berada di Kampung Koto Kandis, Kecamatan Lengayang, Kabupaten Pesisir Selatan yang memanfaatkan sumberdaya sungai sebagai proses dari hasil adaptasi dengan lingkungannya dengan salah satu bentuk pengetahuan yang berkembang.Masyarakat adat Kampung Koto Kandis cukup memahami dan mematuhi prinsipprinsip lingkungan yang hadir dengan adanya lubuk ikan larangan ini seperti prinsip hormat terhadap alam dan memiliki tanggung jawab terhadap alam maupun terhadap keberadaan kelestarian alam khususnya makhluk
hidup.Masyarakat disekitar aliran Sungai Kapalo Banda melalui keputusan adat dan ninik mamak telah menetapkan sebagian wilayah aliran sungai tersebut sebagai wilayah yang dilarang untuk diambil hasil ikannya selama jangka waktu tertentu.

Dampak ekologis dengan adanya kearifan lokal lubuk ikan larangan adalah mencegah kerusakan lingkungan sungai, menanggulangi kerusakan sungai dan memulihkan kerusakan lingkungan. Adanya lubuk ikan larangan oleh masyarakat Kampuang Koto Kandis dipahami sebagai bentukpengamanan sungai dan sebagai bentuk pelestarian ikan terutama ikan lokal yang sudah mulai langka di sungai di wilayah tersebut.

Perlu dikeatahui upaya yang dilakukan dalam menetukan kondisi sungai yang baik dan dapat dijadikan sebagai lubuk larangan. Dalam merencanakan dan membuat lubuk ikan larangan tidak hanya berdasarkan peran dan partisipasi masyarakat saja tetapi juga berdasarkan kepada karakteristik sungainya, karakteristik sungai yang dimaksud adalah berdasarkan kondisi fisik sungai yang dapat dijadikan sebagai pelestarian lubuk ikan larangan. Belum diketahui apakah seluruh sungai yang ada dapat dijadikan sebagai lubuk ikan larangan atau memang ada karakteristik fisik sungai yang ditentukan untuk bisa dijadikan sebagai lubuk larangan, serta apa saja faktor yang mempengaruhi daerah tersebut sehingga dijadikan sebagai lubuk ikan larangan. Sehubungan dengan hal tersebut, maka penulis tertarik untuk mengakaji lebih lanjut mengenai "Lubuk Ikan Larangan Sebagai Bentuk Kearifan Lokal Di Kampung Koto Kandis Kecamatan Lengayang Kabupaten Pesisir Selatan". 


\section{Lubuk Ikan Larangan}

Aturan lubuk larang atau lubuk larangan mengartikan sebuah lubuk, bagian sungai yang berceruk dan menjadi tempat ikan bertelur, dilarang dan dibatasi pengambilan ikannya selama kurun waktu tertentu, atas dasar kesepakatan bersama masyarakat. Secara sederhana orang akan cepat mengartikannya sebagai suatu kawasan tertentu di sungai yang dilindungi dalam masa tertentu (Budiyono, 2011).

Lubuk larangan adalah salah satu kearifan lokal yang dikelola secara bersama dan lubuk larangan tersebut mempunyai badan hukum dan aturanaturan yang disepakati secara bersama yang disepakati oleh pimpinanpimpinan di wilayah tersebut yang meliputi: Ninik Mamak, Pihak Pemerintah Desa, dan Pihak Organisasi Pemuda.Lubuk larangan sebuah lubuk yang dengan disengaja di larang, sedangkan yang disebut dengan lubuk adalah sebuah tempat yang mempunyai kedalaman kurang lebih dari 3 meter, lubuk menjadi tempat persembunyian bagi ikan-ikan (Budiyono, 2011). Berikut ini syaratsyarat pemilihan lokasi perairan untuk budidaya ikan yang baik: 1) Sumber air tawar permukaan yang digunakan untuk budidaya meliputi sungai, saluran, mata air, danau dan waduk. Air permukaan ini cukup baik karena kandungan oksigennya tinggi. 2) Jenis tanah yang paling baik untuk dibuat kolam berupa liat atau liat berpasir. 3) Kemiringan tanah yang dianjurkan untuk pembuatan kolam sekitar 3-5 \%. 4) Ikan sebaiknya dipelihara di daerah yang terletak di ketinggian antara 10500 meter di atas permukaan laut. 5) Air yang digunakan harus bersih, tidak tercemar, dan tidak keruh. 6) Debit air untuk budidaya ikan berkisar antara 10
- $60 \mathrm{~cm} /$ detik adalah cocok. 7) Tingkat keasaman $(\mathrm{pH})$ air yang optimal adalah 7-8 derajat.

\section{Kearifan Lokal}

Kearifan lokal menurut UU No. 32/2009 tentang perlindungan dan pengelolahan lingkungan hidup Bab: I Pasal I Butir 30 adalah: nilai-nilai luhur yang berlaku dalam tata kehidupan masyarakat antara lain melindungi dan mengelolah lingkungan hidup secara lestari.Kearifan lokalmerupakan tata nilai atau perilaku hidup masyarakat lokal dalam berinteraksi dengan lingkungantempatnya hidup secara arif.

Kearifan lokal adalah semuabentuk pengetahuan, keyakinan, pemahaman atau wawasan serta adat kebiasaan atau etika yang menuntun perilaku manusia dalam kehidupan di dalam komunitas ekologis. Semua bentuk kearifan lokal ini dihayati, dipraktekkan, diajarkan dan diwariskan dari generasi ke generasi sekaligus membentuk pola perilaku manusia terhadap sesama manusia, alam maupun gaib (Keraf, 2002).

\section{Sungai}

Sungai sebagai salah satu sumber air mempunyai fungsi yang sangat penting bagi kehidupan dan penghidupan masyarakat. Sungai merupakan tempat-tempat dan wadahwadah serta jaringan pengaliran air mulai dari mata air sampai muara dengan dibatasi kanan dan kirinya serta sepanjang pengalirannya oleh garis sempadan (PP No. 35 Tahun 1991).

Sungai terdiri dari beberapa bagian, bermula dari mata air yang mengalir ke anak sungai. Terdapat beberapa karakter sungai, yaitu: tata nama bagian sungai, orde sungai, 
profil sungai, pola sungai, klasifikasi genetik sungai, dan debit sungai.

\section{METODE PENELITIAN}

Metode yang digunakan dalam penelitian ini adalah metode gabungan(Mixed Method). Penelitian ini merupakan suatu langkah penelitian dengan menggabungkan dua bentuk penelitian yang telah ada sebelumnya yaitu penelitian kuantitatif dan penelitian kualitatif. Mixed method merupakan pendekatan penelitian yang mengkombinasikan antara penelitian kuantitatif dengan penelitian kualitatif (Creswell, 2010).

Kedua metode memiliki keunggulan dan kekurangan masingmasing. Keberadaan kedua metode tidak perlu dipertentangkan karena justru saling melengkapi. Kedua metode tersebut dapat digunakan bersama-sama, dengan kata lain dapat digunakan bersama untuk meneliti pada obyek yang sama, tetapi tujuan yang berbeda dan digunakan secara bergantian (Sugiyono, 2011).

Penelitian ini dilaksanakan pada 22 Mei sampai 22 Juni 2017 bertempat di Kampung Koto Kandis Kecamatan Lengayang Kabupaten Pesisir Selatan yang dijadikan sebagai lubuk ikan larangan. Teknik pengambilan sampel pada penelitian ini yaitu menggunakan cara purposive sampling yaitu pengambilan sampel berdasarkan

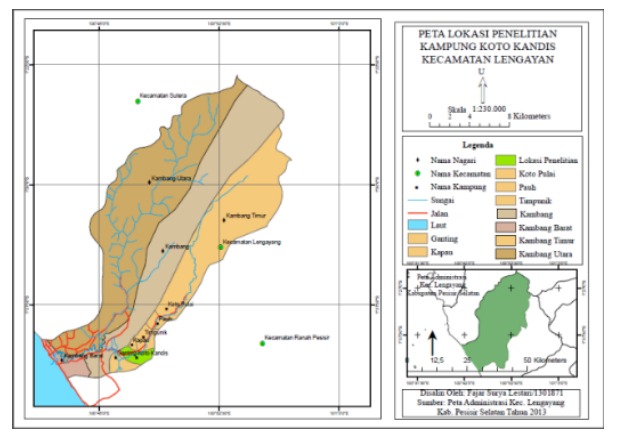

Gambar 1. Sungai yang Mengairi

Lubuk Ikan Larangan

tujuan, pada cara ini siapa yang akan diambil sebagai anggota sampel diserahkan pada pertimbangan pengumpul data yang berdasarkan atas pertimbangannya sesuai dengan maksud dan tujuan penelitian.

Teknik pengumpulan data dalam penelitian ini menggunakan observasi, kuesioner, wawancara, dan dokumentasi. Teknik analisis data yang digunakan pada penelitian ini, yaitu: (1) faktor yang mempengaruhi Kampung Koto Kandis dijadikan sebagai lubuk ikan larangan menggunakan analisis data edit kuesioner dan melakukan tabulasi data, dengan menggunakan rumus: $\mathrm{P}=$ f/N X 100\%. (2) sistem pelaksanaan kearifan lokal pada lubuk ikan larangan di Kampung Koto Kandis dapat dianalisis berdasarkan sumber dan pengumpulan data yang peneliti lakukan melalui wawancara.

\section{HASIL DAN PEMBAHASAN}

Faktor yang Mempengaruhi Koto Kandis Dijadikan Sebagai Lubuk Ikan Larangan

Keberadaan lubuk ikan larangan di Kampung Koto Kandis tidak terlepas dari dua faktor, pertama yaitu faktor yang berasal dari masyarakat Kampung Koto Kandis sendiri dan yang kedua yaitu faktor sungai yang dijadikan sebagai tempat persembunyian ikan-ikan yang dilarang pengambilannya hingga batas waktu yang telah ditentukan.

\section{a) Masyarakat}

Pemikiran, keterlibatan, dan partisipasi masyarakat yang berada di Kampung Koto Kandis telah melahirkan sebuah kearifan lokal yaitu lubuk ikan larangan yang hadir dan diterima oleh seluruh lapisan 
masyarakat. . Berdasarkan data yang didapatkan di lapangan diketahui bahwa pada awal terbentuknya lubuk ikan larangan, masyarakat menjadikan Sungai Kapalo Banda dengan panjang $200 \mathrm{~m}$ dijadikan sebagai lokasi yang tepat untuk lubuk ikan larangan.

Pengelolaan kawasan lubuk ikan larangan mulai dari proses perencanaan, pelaksanaan, dan pengawasannya tidak lepas dari partisipasi seluruh masyarakat. Kerjasama stakeholder juga akan mengefektifkan pengelolaan serta mengefisienkan anggaran. Dalam pertemuan-pertemuan bersama antara stakeholder akan memunculkan keinginan mengsinkronisasikan berbagai program dari para pihak.

Keberadaan lubuk ikan larangan perlu ada monitoring/ pegawasan. Pengawasan ini bertujuan untuk memantau orang-orang yang tidak bertanggung jawab yaitu mengambil ikan sebelum waktu yang ditentukan. Berdasarkan hasil penelitian diketahui bahwa seluruh masyarakat Kampung Koto Kandis memilki hak yang sama dalam mengawasi lubuk ikan larangan, bagi salah seorang masyarakat ada yang mengetahui bahwa terjadi pengambilan ikan di lubuk ikan larangan sebelum waktu yang ditentukan, maka masyarakat wajib untuk melaporkan pelaku yang mengambil ikan di dalam areal yang telah ditetapkan sebagai lubuk ikan larangan.

\section{b) Karakteristik Fisik Sungai Kapalo Banda}

Sungai Kapalo Banda memiliki ciri-ciri kondisi fisik sungai sebagai berikut: Sungai Kapalo Banda ini merupakan induk sungai yang aliran air sungainya langsung dari perbukitan, sungai ini termasuk kedalam orde sungai I, karena dari hulu sungai hingga ke Sungai Kapalo Banda tidak memiliki cabang atau alur sungai yang lain, dijumpai di bagian pertengahan alur sungai, pada bagaian sungai ini juga terjadi pengurangan kecepatan aliran air karena ketinggian relief yang berkurang, dan sudah mulai timbul pengendapan pada tempat yang datar, Sungai Kapalo Banda yang hampir mendekati hilir sungai, alus air yang mengalir tidak terlalu deras dan tidak cukup kuat untuk menempuh jarak yang lurus, jarak alirannya biasanya pendekpendek dan terletak diantara aliran sungai induk dengan aliran anak-anak sungainya, mengalir mengikuti kemiringan lapisan batuan yang dilaluinya, terdapat empat tingkatan ketinggian lereng pada daerah yang dilalui Sungai Kapalo Banda, keempat tingkatan ketinggian lereng tersebut yaitu: datar, kemiringan sedang, kemiringan tinggi, dan daerah yang berlereng curam, dan lubuk ikan larangan diketahui seluas $6.600 \mathrm{~m}$.

\section{Sistem Pelaksanaan Kearifan Lokal Lubuk Ikan Larangan di Kampung Koto Kandis}

Sistem pelaksanaan kearifan lokal lubuk ikan larangan yang berada di Kampung Koto Kandis pertama kali diadakan pada tahun 2007 telah melalui kesepakatan masyarakat yang berada di Kampung Koto Kandis. Pada awalnya, dikatakanlah bahwa lubuk larangan ini menggunakan unsur mistis, hal ini bertujuan supaya tidak ada masyarakat yang berada di dalam Kampung Koto Kandis maupun di luar Kampung Koto Kandis yang berani mengambil ikan menggunakan alat apapun selama waktu satu tahun, namun yang terjadisesungguhnya adalah di lubuk larangan ini tidak terdapat unsur mistis apapun. Masyarakat hanya mempercayai, 
memberikan ketenangang, dan makanan kepada ikan yang berada di dalam lubuk larangan, dengan begitu ikan-ikan tersebut tetap berada di lubuk seluas $6.600 \mathrm{~m}$ tersebut. Hal tersebut merupakan perilaku masyarakat terhadap ikan larangan, masayarakat memberikan kenyamanan dengan tidak mengganggu kehidupan ikan, sehingga ikan-ikan tersebut terbiasa hidup di lubuk larangan.

\section{KESIMPULAN}

Faktor yang mempengaruhi daerah tersebut dijadikan lubuk larangan terfokus kepada dua faktor, yaitu: pertama faktor masyarakat Koto Kandis yang berawal dari pemikiran, musyawarah, perencanaan, pengawasan, dan kerjasama masyarakat maka terbentuklah lubuk ikan larangan di Sungai Kapalo Banda Kampung Koto Kandis. Kedua, faktor kondisi fisik Singai Kapalo Banda yang dijadikan lubuk ikan larangan memiliki ciri fisik sungai sebagai berikut: Sungai Kapalo Banda merupakan alur induk sungai dan merupakan sungai orde I karena tidak ditemui cabang sungai lainnya, sungai ini dijumpai di bagian pertengahan alur sungai yang terletak diantara aliran sungai induk dan anak sungai dan terjadi pengurangan kecepatan aliran serta mulai timbul pengendapan di beberapa tempat, sungai ini mengalir mengikuti kemiringan lapisan batuan, dan topografi daerah sekitar sungai didominasi oleh lereng yang datar.

Sistem pelaksanaan kearifan lokal lubuk ikan larangan di Kampung Koto Kandis diterima dan dibentuk pada tahun 2007 oleh masyarakat Koto Kandis, masyarakat hanya percaya, lalu memberikan ketenangan, dan makanan untuk ikan-ikan sehingga ikan-ikan tersebut terbiasa hidup dan tidak merasa terganggu. Pada awalnya dikatakanlah bahwa lubuk larangan ini menggunakan unsur mistis, hal ini bertujuan agar tidak ada masyarakat yang mengambil ikan, namun faktanya lubuk ini tidak menggunakan unsur mistis apapun.

\section{DAFTAR PUSTAKA}

Alus, C. (2014). Peran Lembaga Adat dalam Pelestarian Kearifan Lokal Suku Sahu Kabupaten Halmahera Barat. Actua Diurna, 1-15.

Diana Sari, I. J. (2016). Pengelolaan Lubuk Larangan sebagai Upaya Konservasi Perairan di Desa Rantau Pandan Kabupaten Bungo Jambi. Dinamika Lingkungan Indonesia, 9-15.

Firdaus, M. (2015). Pengelolaan Sumberdaya Ikan Sungai. Marina, 35-45.

Miles, Matthew, dan Michael Huberman. 1992. Analisa Data Kualitatif (Terjemahan). Jakarta: UI Press.

Moleong, Lexi J. 2005. Metodologi Penelitian Kualitatif. Bandung. Remaja karya.

Pawarti, A. (2012). Nilai Pelestarian Lingkungan dalam Kearifan Lokal Lubuk Larangan Ngalau Agung. Prosiding Seminar Nasional Pengelolaan Sumberdaya Alam dan Lingkungan, 98-103.

Sugiyono, P. D. (2010). Metode Penelitian Kombinasi (Mixed Methods). Bandung:Alfabeta. 